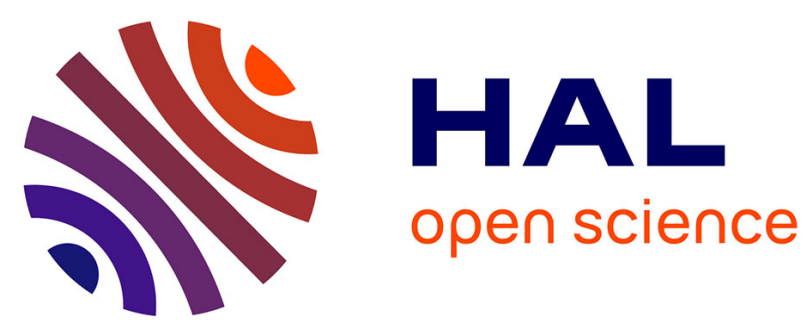

\title{
Ultralow Lattice Thermal Conductivity and Enhanced Thermoelectric Performance in SnTe:Ga Materials
}

Rabih Al Rahal Al Orabi, Junphil Hwang, Chan-Chieh Lin, Regis Gautier, Bruno Fontaine, Woochul Kim, Jong-Soo Rhyee, Daehyun Wee, Marco Fornari

\section{To cite this version:}

Rabih Al Rahal Al Orabi, Junphil Hwang, Chan-Chieh Lin, Regis Gautier, Bruno Fontaine, et al.. Ultralow Lattice Thermal Conductivity and Enhanced Thermoelectric Performance in SnTe:Ga Materials. Chemistry of Materials, 2017, 29 (2), pp.612-620. 10.1021/acs.chemmater.6b04076 . hal01500409

HAL Id: hal-01500409

https://hal-univ-rennes1.archives-ouvertes.fr/hal-01500409

Submitted on 22 May 2017

HAL is a multi-disciplinary open access archive for the deposit and dissemination of scientific research documents, whether they are published or not. The documents may come from teaching and research institutions in France or abroad, or from public or private research centers.
L'archive ouverte pluridisciplinaire HAL, est destinée au dépôt et à la diffusion de documents scientifiques de niveau recherche, publiés ou non, émanant des établissements d'enseignement et de recherche français ou étrangers, des laboratoires publics ou privés. 


\title{
Ultra-low Lattice Thermal Conductivity and
}

\section{Enhanced Thermoelectric Performance in}

\section{SnTe:Ga Materials}

\author{
Rabih Al Rahal Al Orabi, ${ }^{, \dagger}, \ddagger$ Junphil Hwang, "Chan-Chieh Lin, ${ }^{\S}$ Régis Gautier, \\ Bruno Fontaine," Woochul Kim, ${ }^{\uparrow}$ Jong-Soo Rhyee, ${ }^{\S}$ Daehyun Wee, ${ }^{\dagger}$ and Marco
} Fornari*, ${ }^{*}$

Department of Environmental Science and Engineering, Ewha Womans University, Seoul, 120-750, Korea, Department of Physics, Central Michigan University, Mt. Pleasant, MI 48859, USA, School of Mechanical Engineering, Yonsei University, Seoul, 120-749, Korea, Department of Applied Physics, College of Applied Science, Kyung Hee University, Yongin-si, Giheung-gi, Gyeonggi-do 446-701, Korea, Institut des Sciences Chimiques de Rennes, UMR 6226 CNRS-Université de Rennes 1-Ecole Nationale Supérieure de Chimie de Rennes, 11 allé de Beaulieu, CS 50837, F-35708 Rennes, France., and Department of Physics and Science of Advanced Materials Program, Central Michigan University, Mt. Pleasant, MI 48859, USA

E-mail: alrah1r@cmich.edu; marco.fornari@cmich.edu

\footnotetext{
${ }^{*}$ To whom correspondence should be addressed

${ }^{\dagger}$ Department of Environmental Science and Engineering, Ewha Womans University, Seoul, 120-750, Korea

${ }^{\ddagger}$ Department of Physics, Central Michigan University, Mt. Pleasant, MI 48859, USA

"School of Mechanical Engineering, Yonsei University, Seoul, 120-749, Korea

${ }^{\S}$ Department of Applied Physics, College of Applied Science, Kyung Hee University, Yongin-si, Giheunggi, Gyeonggi-do 446-701, Korea

"Institut des Sciences Chimiques de Rennes, UMR 6226 CNRS-Université de Rennes 1-Ecole Nationale Supérieure de Chimie de Rennes, 11 allé de Beaulieu, CS 50837, F-35708 Rennes, France.

${ }^{\perp}$ Department of Physics and Science of Advanced Materials Program, Central Michigan University, Mt.
} 


\begin{abstract}
Ultra-low thermal conductivity is of great interest in a variety of field including thermoelectric energy conversion. We report, for the first time, experimental evidence that Ga-doping in SnTe may lower the lattice thermal conduction slightly below the theoretical amorphous minimum at high temperature. Such an effect is justified by the spontaneous formation of nano-precipitates we characterized as GaTe. Remarkably, the introduction of $\mathrm{Ga}(2-10 \%)$ in SnTe also improves the electronic transport properties by activating several hole pockets in the multi-valley valence band. Experimental results are supported with density functional theory calculations. The thermoelectric figure of merit, $Z T$, reaches $\sim 1$ at $873 \mathrm{~K}$ in $\mathrm{Sn}_{0.96} \mathrm{Ga}_{0.07} \mathrm{Te}$, which corresponds to a $\sim 80 \%$ improvement with respect to pure $\mathrm{SnTe}$.
\end{abstract}

\title{
Introduction
}

The thermoelectric effect refers to the direct conversion of a temperature gradient into electrical current or, conversely, the generation of a heat flux by applying an electric field. ${ }^{1-4}$ This solid-state technology has a long history of powering spacecrafts in deep space missions and is now being actively developed for waste heat recovery in automotive systems and industrial plants. The performance of a thermoelectric material is described by the dimensionless thermoelectric figure of merit, $Z T=S^{2} \sigma T /\left(k_{e}+k_{l}\right)$, where $S, \sigma$, and $k_{e}+k_{l}$ stand for the Seebeck coefficient, the electrical conductivity, and the electronic $\left(k_{e}\right)$ and lattice $\left(k_{l}\right)$ components of the thermal conductivity. $T$ is the temperature at which the device is operating. Two main approaches have been used to enhance $Z T$ and improve the efficiency of energy conversion: (1) the optimization of the power factor, $S^{2} \sigma$, by engineering the electronic properties ${ }^{5-9}$ and/or (2) the minimization of $k_{l}$ via alloying, tuning of the bond anharmonicities, and nanostructuring. ${ }^{8,10-22}$ These approaches lead to a figure of merit $Z T$ in excess of 2 in lead chalcogenides, $\mathrm{PbQ}(\mathrm{Q}=\mathrm{S}, \mathrm{Se}, \mathrm{Te}) .{ }^{23-30}$

Pleasant, MI 48859, USA 
Recently, tin based chalcogenides have been proposed as alternative to $\mathrm{PbQ}$ in thermoelectric power generation because they do not raise environmental concerns associated with $\mathrm{Pb}$ toxicity. ${ }^{5-9,31,32}$ Among tin chalcogenides only SnTe adopts the same rock salt structure as $\mathrm{PbQ}$ but it exhibits $Z T \sim 0.40$ at $900 \mathrm{~K} .{ }^{33}$ The low value of $Z T$ was attributed to a high carrier concentration $\left(10^{20}-10^{21} \mathrm{~cm}^{-3}\right)$ caused by intrinsic Sn vacancies combined with a large separation in energy between valence bands with heavy and light effective masses ${ }^{34,35}$ which limits the Seebeck coefficient. In addition, the small energy band gap $(\sim 0.18 \mathrm{eV})^{36,37}$ is favoring bipolar transport. The limitations of pure SnTe were overcome either by creating resonant states in the electronic density of states or by controlling the energy of the hole pockets at the top of the valence band. ${ }^{5-7,9,38-41}$

The experimental thermal conductivity of pristine $\mathrm{SnTe}$ is $\sim 2.88 \mathrm{Wm}^{-1} \mathrm{~K}^{-1}$ at room temperature. ${ }^{38}$ For good thermoelectric performances, values just above the theoretical amorphous limit (for SnTe, $k_{\text {min }}$ is equal to $0.5 \mathrm{Wm}^{-1} \mathrm{~K}^{-1}$ ) ${ }^{6}$ are required. Recently, $k_{l}$ has been successfully reduced via vacancy scattering, ${ }^{42}$ alloying formation or/and the introduction of the second phase nano-precipitates in few SnTe based materials, $, 5,3,38,42-46,46$ however, to the best of our knowledge, the amorphous limit was never reached. Here, we report for the first time the reduction of $k_{l}$ to $\sim 0.455 \mathrm{Wm}^{-1} \mathrm{~K}^{-1}$ at $\mathrm{T} \geq 776 \mathrm{~K}$ for Ga-doped SnTe, slightly below the theoretical $k_{\text {min }}$ for SnTe. ${ }^{6}$

Ga doping has been well investigated in $n$-type PbSe and significantly improved of the power factors compared to those of pristine PbSe. The similarities in band and crystal structures between PbSe and SnTe hinted that Ga-doping could favorably modify the electronic properties. ${ }^{47}$ Zhao et al. ${ }^{44}$ recently suggested the substitution of a small amounts (3\%) of Sn with Ga decreases the lattice thermal conductivity from $3.2 \mathrm{Wm}^{-1} \mathrm{~K}^{-1}$ to $2 \mathrm{Wm}^{-1} \mathrm{~K}^{-1}$ at room temperature in SnTe. We were able to increase the Ga content in SnTe up to $10 \%$ and exploit the increased disorder to reach $k_{m i n}$. In addition, we show that Ga doping in SnTe improves the electronic properties by activating several hole pockets with larger effective masses, resulting in an enhanced Seebeck coefficient and power factor. Overall, an 
optimized thermoelectric figure of merit $Z T$ of 0.99 has been achieved at $873 \mathrm{~K}$ for $7 \%$ Gadoped SnTe sample, which make the heavily doped $\mathrm{Sn}_{1.03-x} \mathrm{Ga}_{x}$ Te system attractive for the mid-temperature thermoelectric power generation.

\section{Experimental procedures}

\section{Samples preparation}

Recently, Tan et al. ${ }^{38}$ have shown that Sn self-compensation is an effective path for enhancing the thermoelectric performance of SnTe by decreasing the hole carrier density. High quality ingots with nominal compositions of $\mathrm{Sn}_{1.03-x} \mathrm{Ga}_{x} \mathrm{Te}(\mathrm{x}=0,0.02,0.03,0.05,0.07$ and 0.1$)$ were synthesized by mixing appropriate ratios of high purity elemental precursors from Sn shot $(99.999+\%)$, Ga shot $(99.5+\%)$ and Te shot $(99.999+\%)$ in silica tubes. The tubes were then evacuated to a residual pressure of $\sim 10^{-4}$ Torr, flame sealed and slowly heated to $1023 \mathrm{~K}$, soaked at this temperature for $3 \mathrm{~h}$, then heated up to $1273 \mathrm{~K}$ in $3 \mathrm{~h}$, soaked for $10 \mathrm{~h}$ to ensure the homogeneity of composition and subsequently quenched in ice water.

The obtained samples of $\mathrm{Sn}_{1.03-x} \mathrm{Ga}_{x}$ Te were ground into fine powders and then densified by sintering (at $\sim 10^{-2}$ mbar) via hot uniaxial pressing (HUP). The pressing conditions were as follows: the pressure was applied from the beginning of the temperature ramp to the end of the high-temperature dwell. A typical quantity of $10 \mathrm{~g}$ of powder was introduced into 12 mm diameter graphite dies previously coated with boron nitride. The applied load was 50 $\mathrm{MPa}$ at $800 \mathrm{~K}$ for $2 \mathrm{~h}$ for all experiments. The densities for all pellets were calculated to be $95 \%$ of the theoretical values after measuring volume and weight.

\section{Powder X-ray diffraction and scanning electron microscopy}

Samples were characterized by powder X-ray diffraction (PXRD) with $\mathrm{Cu} \mathrm{K}_{\alpha}(\lambda=1.5406$ A) radiation at room temperature using a Bruker D8 diffractometer. Lattice constants and volumes were calculated by Rietveld refinement using the Fullprof software. Scanning 
electron microscopy energy dispersive spectroscopy (EDS) imaging were carried out using a JSM-6701F microscope.

\section{Electrical transport measurements}

The HUPed pellets were cut into $\sim 3.5 \mathrm{~mm}$ x $3.5 \mathrm{~mm}$ x $10 \mathrm{~mm}$ bars for simultaneous measurement of the electrical conductivity and the Seebeck coefficient. Measurements were performed under He atmosphere from room temperature to $873 \mathrm{~K}$ using a Ulvac Riko ZEM-3 instrument. The room temperature Hall coefficients were measured using a PPMS system. Four-contact Hall-bar geometry was used for the measurement. The effective carrier concentration $\left(N_{p}\right)$ was estimated using the relationship $N_{p}=1 / e R_{H}$, where $e$ is the electronic charge and $R_{H}$ is the Hall coefficient. The Hall mobility $\left(\mu_{H}\right)$ was calculated using the relationship $\mu_{H}=\sigma R_{H}$ with $\sigma$ being the electrical conductivity.

\section{Thermal transport measurements}

The HUPed pellets were cut and polished into a squared-shaped of $\sim 10 \mathrm{~mm}$ x $10 \mathrm{~mm} \mathrm{x}$ $1 \mathrm{~mm}$ and cylinder-shaped of $\sim 12 \mathrm{~mm}$ in diameter and $1 \mathrm{~mm}$ thick for thermal diffusivity measurements. The thermal diffusivity coefficient $(D)$ was measured with a laser flash diffusivity method using apparatus (Netzsch LFA 457). The heat capacity $\left(C_{p}\right)$ was obtained by $C_{p}=C_{p, 300}+C_{p 1} \times\left((T / 300)^{\alpha}-1\right) /\left((T / 300)^{\alpha}+C_{p 1} / C_{p, 300}\right),{ }^{48}$ where $T$ is the absolute temperature and $C_{p, 300}$ is the specific heat capacity at $300 \mathrm{~K}$. For $\mathrm{Sn}_{1.03} \mathrm{Te}, C_{p, 300}$ is 0.1973 $\mathrm{Jg}^{-1} \mathrm{~K}^{-1}, C_{p 1}$ is $0.0531 \mathrm{Jg}^{-1} \mathrm{~K}^{-1}$ (calculated using the specific heat measurement for $\mathrm{Sn}_{1.03} \mathrm{Te}$ previously reported by Tan et al. ${ }^{46}$ ). The parameter $\alpha$ is 0.63 . The total thermal conductivity, $k$, was calculated using the formula $k=D C_{p} \mathrm{~d}$ where $\mathrm{d}$ represents the density of the sample. The uncertainty of the thermal conductivity was estimated to be within $8 \%$, considering the uncertainties from $D, C_{p}$, and d. The combined uncertainty for all measurements involved in the calculation of $Z T$ is less than $15 \%$. 


\section{Computational procedures}

\section{First principles calculations}

Our calculations are based on density functional theory (DFT). We used the full-potential linearized augmented plane wave (FLAPW) approach, as implemented in the WIEN2K code. ${ }^{49}$ The muffin-tin radii $\left(\mathrm{R}_{M T}\right)$ were chosen small enough to avoid overlapping during the structural optimization. A plane-wave cutoff corresponding to $\mathrm{R}_{M T} \mathrm{~K}_{\max }=7$ was used in all calculations. The radial wave functions inside the non-overlapping muffin-tin spheres were expanded up to $l_{\max }=12$. Total energy convergence was achieved with respect to the Brillouin zone (BZ) integration mesh with $500 k$-points.

Structure relaxations were performed using the PBE functional for the 64-atoms cubic supercells for $\mathrm{Sn}_{32} \mathrm{Te}_{32}$, and $\mathrm{Sn}_{30} \mathrm{Ga}_{2} \mathrm{Te}_{32}(\sim 6 \mathrm{~mol} \%$ Ga-doped) with Ga atoms substituted for $\mathrm{Sn}$ atoms in SnTe. The Ga sublattice was simple cubic for $\mathrm{Sn}_{32} \mathrm{Te}_{32}$, body-centered cubic for $\mathrm{Sn}_{30} \mathrm{Ga}_{2} \mathrm{Te}_{32}$. During the geometry optimization, both the atomic positions and lattice constant were fully relaxed until forces acting on all atoms become less than $0.02 \mathrm{eV} / \AA$.

For the electronic band structures we used the modified Becke-Johnson (mBJ) functional which leads to excellent agreement with the experimental values for the energy separation between the highest occupied molecular orbital (HOMO) and the lowest unoccupied molecular orbital (LUMO). ${ }^{50}$ We represented the band structures along the high symmetry lines of the cubic Brillouin zone (supercell) for direct analysis of the effects of Sn-Ga substitutions. We used $20000 k$-points in the BZ to compute the density of states (PDOS).

\section{Results and discussion}

PXRD analysis indicates that, within the detection limit, the $\mathrm{Sn}_{1.03-x} \mathrm{Ga}_{x}$ Te samples exhibit single phase rock-salt SnTe structures for Ga concentration below 5\% ( $\leq \leq 0.05$, Figure 1a). At higher Ga content (x $>0.5)$, secondary phase peaks appear (Figure 1a for $25^{\circ} \leq 2 \theta \leq 30^{\circ}$ ) 
which match with the PXRD pattern of GaTe (Figure 1c). The lattice parameters decreases linearly with the increase of Ga content, consistently with the smaller ionic radius of Ga compared to that of Sn. Vegard's law (Figure 1b) describes well the variation of lattice parameters up to $\mathrm{x}=0.05$. Above that concentration the data deviate. Data indicate a uniform solid solution between GaTe and SnTe for $\mathrm{x} \leq 0.05$. For $\mathrm{x}>0.05$, SnTe-GaTe is partly alloyed and partly phase separated. Ga solubility in SnTe (estimated with PXRD) is substantially lower than $\mathrm{Ca}, \mathrm{Mg}$ and $\mathrm{Mn}(\sim 12 \mathrm{~mol} \%)$ and larger than that of $\mathrm{Cd}$ and $\mathrm{Hg}(\sim 3 \mathrm{~mol} \%)^{5-7,9,38}$ doped SnTe. Morphological features at the nanoscale were observed with high resolution SEM as discussed later in this article.

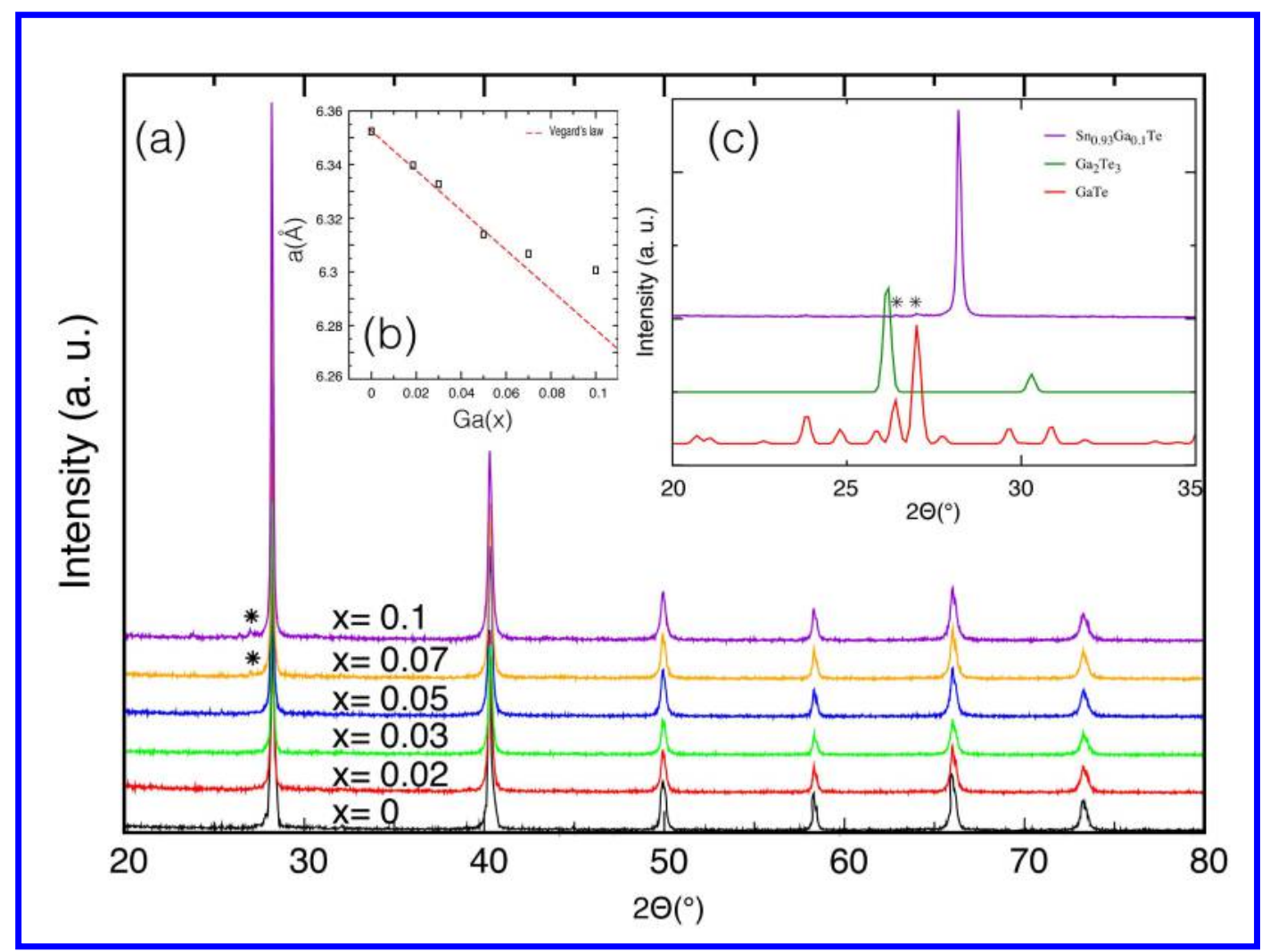

Figure 1: (a) Powder X-ray diffraction patterns of $\mathrm{Sn}_{1.03-x} \mathrm{Ga}_{x} \mathrm{Te}$ samples $(\mathrm{x}=0.00,0.02,0.03,0.05$, 0.07 and 0.1). (b) Lattice parameter as function of Ga concentration; the red dashed line indicates the Vegard's law for the solid solution. (c) Close-up showing the patterns of $\mathrm{Sn}_{0.93} \mathrm{Ga}_{0.1} \mathrm{Te}$, GaTe, and $\mathrm{Ga}_{2} \mathrm{Te}_{3}$ compounds.

Figure 2 displays the total $\left(k_{t o t}\right.$, panel a) and lattice thermal conductivity $\left(k_{l}\right.$, panel b) as a function of temperature for for $\mathrm{Sn}_{1.03-x} \mathrm{Ga}_{x}$ Te samples. The substitution of Ga in 
SnTe substantially reduces the total thermal conductivity from $8.1 \mathrm{~W} / \mathrm{mK}$ to $6.2 \mathrm{~W} / \mathrm{mK}$ at room temperature and from $2.7 \mathrm{~W} / \mathrm{mK}$ to $\sim 2.27 \mathrm{~W} / \mathrm{mK}$ at $873 \mathrm{~K}$. This reduction in $k_{\text {tot }}$ is attributed to the significant reduction of $k_{l}$. The electrical thermal conductivity is proportional to the electrical conductivity according to the Wiedemann-Franz relation $k_{e}=\sigma L T$. Here, the Lorenz number, $L$, was estimated as a function of temperature from the experimental Seebeck coefficients using the single parabolic band model and assuming that acoustic phonon scattering limits the mobility as explained in previous literature (Figure $2 \mathrm{~d}$ in SI). ${ }^{51}$ The lattice thermal conductivity decreases with increasing Ga concentration, presumably because of the concomitant increase of the alloy disorder and, possibly, the contribution of interfacial phonon scattering. The samples with $7 \%$ and $10 \%$ Ga doping exhibit the lowest lattice thermal conductivity of $\sim 0.48 \mathrm{~W} / \mathrm{mK}$ at $723 \mathrm{~K}$, just below the theoretical minimum lattice thermal conductivity for SnTe which was estimated using the model proposed by Cahill et al. ${ }^{52}$ The reduction of $k_{l}$ is about $\sim 75 \%$ for heavily Ga doped SnTe samples, reaching values far below $k_{l}$ reported previously in $\mathrm{In}-/ \mathrm{Cd}-/ \mathrm{Mn} / \mathrm{Mg}$ and Sbdoped SnTe (Figure 2d) and comparable only to the values achieved recently in PbTe by SrTe alloying. ${ }^{5,6,38,43,44,53,54}$

The Klemen's model ${ }^{55,56}$ of disordered alloys was applied to predict the variation of the lattice thermal conductivity (at room temperature) of the $\mathrm{Sn}_{1.03-x} \mathrm{Ga}_{x} \mathrm{Te}$ samples as function of the Ga concentration (Figure 2c). The input parameters used for the calculation are listed on the table 1 (See SI) . For $x \leq 0.05$, experimental $k_{l}$ values agree well with the Klemens model, indicating that the point defect scattering caused by Ga alloying is the dominant factor at small Ga content. However, when $x>0.05$, the experimental $k_{l}$ values fall below the Klemens model, indicating that additional mechanisms associated with nanoscale precipates contribute to the phonon scattering. ${ }^{8,10-14}$ 

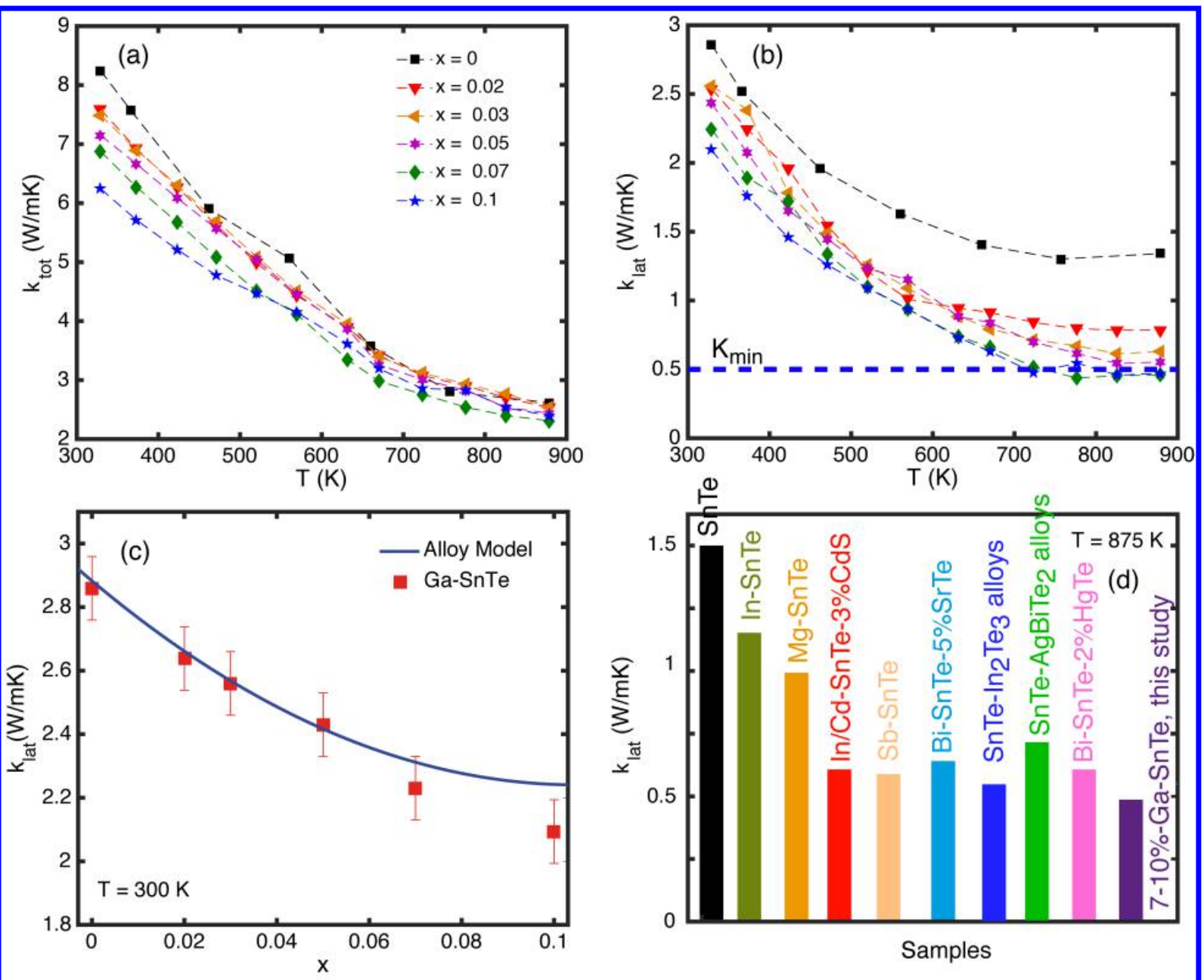

Figure 2: Temperature dependence of (a) total thermal conductivity and (b) lattice thermal conductivity for $\mathrm{Sn}_{1.03-x} \mathrm{Ga}_{x} \mathrm{Te}(\mathrm{x}=0,0.02,0.03,0.05,0.07$ and 0.1) samples. (c) Room temperature lattice thermal conductivity as function of Ga concentration. Error bars are indicated (10\%). The dashed blue line corresponds to the theoretical amorphous limit ${ }^{57}$ ) for $\mathrm{Sn}_{1.03-x} \mathrm{Ga}_{x} \mathrm{Te} .{ }^{55,56}$ (d) Comparison of the hight temperature $k_{\text {lat }}$ of the $7 \%$ and $10 \%$ Ga-doped SnTe samples with the values reported for $\mathrm{In} / \mathrm{Mg} / \mathrm{In}-\mathrm{Cd} / \mathrm{Bi}-3 \% \mathrm{SrTe} / \mathrm{Bi}-2 \% \mathrm{HgTe}$ doped $\mathrm{SnTe},{ }^{5,6,38,43-45}$ and $\mathrm{SnTe}-\mathrm{In}_{2} \mathrm{Te}_{3}, \mathrm{SnTe}^{-\mathrm{AgBiTe}} 2$ alloy materials. ${ }^{42,46}$

In order to explicate the mechanism behind the observed low lattice thermal conductivity in Ga-doped SnTe, we performed the SEM/EDS analysis of pure, 5\%, and 10\% Ga-doped SnTe (see Figure 3). The SEM images for $\mathrm{Sn}_{1.03}$ Te and $\mathrm{Sn}_{0.98} \mathrm{Ga}_{0.05}$ Te show uniform samples with no obvious nanoscale precipitates in the matrix; this result is consistent with the PXRD results shown in Figure 1 and Figure 1 a,d,f in SI. For 10\% Ga doping, we observed numerous nanoscale precipitates (highlighted by the red circles, Figure 3c). The EDS element mapping (Figure 3d) indicates Te, Ga, and Sn distribution respectively pointing to the chemical 
composition of precipitates which are rich in Ga, but deficient in Sn. Tellurium distribution is uniform across the sample. We consider this an indication that the inhomogeneities within the matrix effectively decrease the lattice thermal conductivity (Figure 2c) and lead to improved thermoelectric performance.

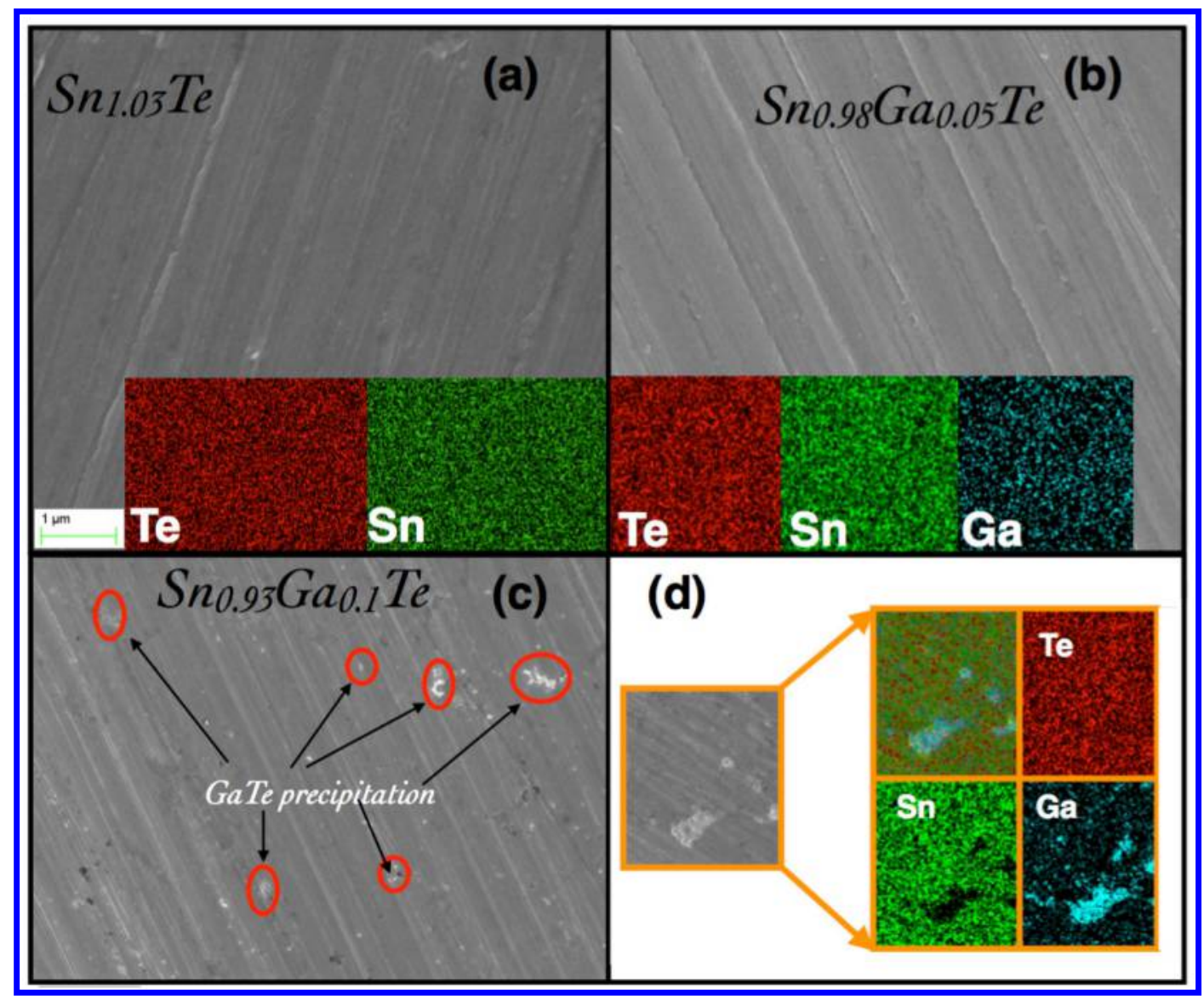

Figure 3: (a) SEM/EDS images of $\mathrm{Sn}_{1.03} \mathrm{Te}$, (b) $\mathrm{Sn}_{0.98} \mathrm{Ca}_{0.05} \mathrm{Te}$, (c) $\mathrm{Sn}_{0.93} \mathrm{Ca}_{0.1} \mathrm{Te}$ samples and (d) GaTe precipitates in $\mathrm{Sn}_{0.93} \mathrm{Ca}_{0.1}$ Te sample, shows the SEM/EDS mapping of Te, Ga, and Sn edges

Figure 4 shows the temperature dependent electrical transport properties of $\mathrm{Sn}_{1.03-x} \mathrm{Ga}_{x} \mathrm{Te}$ samples. As expected in a degenerate semiconductor, the electrical conductivity, $\sigma$, decreases with increasing temperature (Figure 4 a). The presence of Ga introduces scattering phenomena in SnTe leading to a decrease in $\sigma$ from $8766 \mathrm{~S} \mathrm{~cm}^{-1}$ to $5483 \mathrm{~S} \mathrm{~cm}^{-1}$ at room temperature, while the electrical conductivities at high temperature for all Ga-doped samples are only slightly smaller than in pure SnTe. Similar trend was found on the Ca, Cd, and Mn 
2

3

4

5

6

10

11

12

13

14

15

16

17

18

19

20

21

22

23

24

25

26

27

28

29

30

31

32

33

34

35

36

37

38

39

40

41

42

43

44

45

46

47

48

49

50

51

52

53

54

55

56

57

58

59

60

doped SnTe. ${ }^{5-7,9,38}$

The room temperature carrier concentrations $\left(N_{p}\right)$ are shown in Figures $4 \mathrm{~b}$. For all $\mathrm{Sn}_{1.03-x} \mathrm{Ga}_{x} \mathrm{Te}(0 \leq \mathrm{x} \leq 0.09)$ samples, the room temperature Hall coefficients, $R_{H}$, are positive, as expected for $p$-type carriers. The $N_{p}$ at $300 \mathrm{~K}$ increase gradually with increasing concentration until $7 \%$ and then decrease for $10 \%$ concentration. Anomalous changes in the carrier concentration with the increase of $\mathrm{Ga}$ concentration are difficult to explain but we can conjecture that the presence of substitutional defects influences the formation energy of the vacancies. A similar phenomena was observed recently with $\mathrm{In}, \mathrm{Mg}, \mathrm{Cd}$, $\mathrm{Ca}$ and $\mathrm{Hg}$, Mn doped in SnTe. ${ }^{5,6,9,38}$ The room temperature mobilities $\left(\mu_{H}\right)$ of $\operatorname{Sn}_{1.03-x} \mathrm{Ga}_{x}$ Te samples are presented in Figure 4c. We observe a reduction in $\mu_{H}$ with increasing Ga doping which accounts for the reduced electrical conductivity in highly doped samples. The gradual loss of mobility in SnTe with increasing Ga content may be caused by increased point defect scattering within solid solution or interfacial scattering caused by GaTe nano-precipitates for $\mathrm{x}=7-10 \%$. 


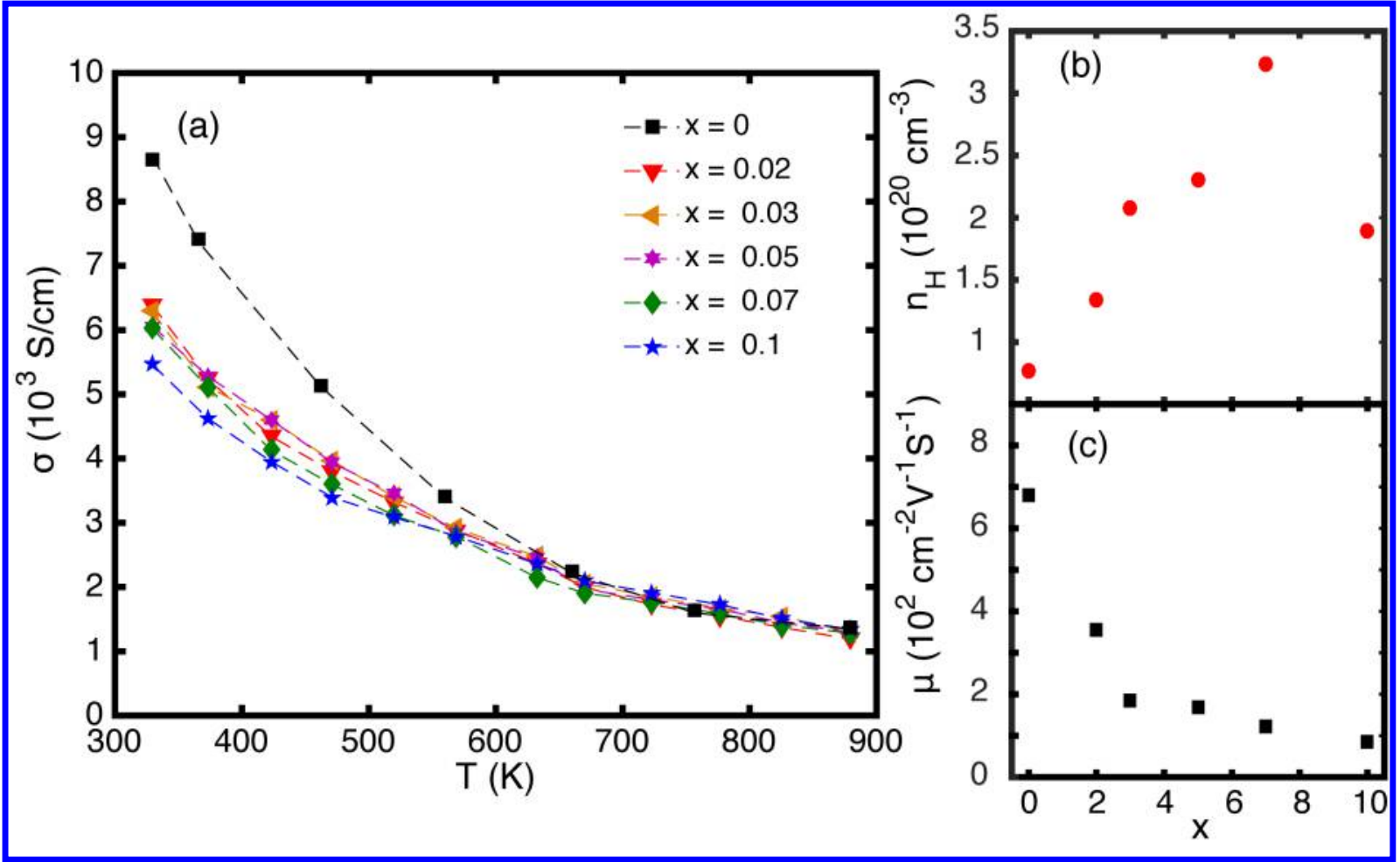

Figure 4: (a) Temperature dependence of electrical conductivity in $\mathrm{Sn}_{1.03-x} \mathrm{Ga}_{x} \mathrm{Te}$ samples. (b) Carrier concentration $\left(N_{p}\right)$ and (c) carrier mobility $(\mu)$ at room temperature with respect to Ga alloying concentration $(\mathrm{x})$.

We studied also the temperature dependence of the Seebeck coefficient for all our samples (Figure 5a). A positive values of Seebeck coefficient for all samples indicates the $p$-type conduction in the temperature range studies of 300-873 K. The Seebeck coefficients are consistent with hole conductivity and increase almost linearly with temperature. As mentioned earlier, the pristine SnTe exhibits a low Seebeck coefficent of $\sim 15 \mu V / K$ at $300 \mathrm{~K}$ and reach the maximum value of $\sim 140 \mu V / K$ at $873 \mathrm{~K}$. The introduction of $\mathrm{Ga}$ in $\mathrm{Sn}_{1.03}$ Te leads to a remarkable enhancement in $S$ at both low and high temperature: the improvement is up to $23 \mu V / K$ at room temperature and greater than $40 \mu V / K$ at high temperature. The effectiveness of Ga alloying is reflected in the carriers' effective mass $\left(\mathrm{m}^{*}\right)$ that we derived for each sample using the room temperature $S$ and $N_{p}$, and considering a single parabolic band model. ${ }^{51,58}$ Using the Seebeck coefficient, the chemical potential $(\mu)$ can be estimated using eq 1 with $\left(\lambda=0\right.$, acoustic-phonon scattering), where $F_{j}(\mu)$ are the Fermi integrals given in eq 2. The hole effective mass can then be determined from eq 3 using the measured 
carrier concentration $\left(N_{p}\right)$.

$$
\begin{gathered}
S=\frac{k_{B}}{e}\left\{\frac{(2+\lambda) F_{1+\lambda}(\mu)}{(1+\lambda) F_{\lambda}(\mu)}-\mu\right\} \\
F_{j}(\mu)=\int_{0}^{\infty} \frac{\zeta^{j} d \zeta}{1+e^{(\zeta-\mu)}} \\
m^{*}=\frac{h^{2}}{2 k_{B} T}\left[\frac{N_{p}}{4 \pi F_{1 / 2}(\mu)}\right]^{2 / 3}
\end{gathered}
$$

The $\mathrm{m}^{*}$ increases gradually from $0.133 \mathrm{~m}_{e}$ to $0.8 \mathrm{~m}_{e}\left(\mathrm{~m}_{e}\right.$ is the free electron mass) with increasing Ga content from 0 to $10 \mathrm{~mol} \%$ (Table 1), which is resulting probably due to the increasing contribution of several hole pockets in the multi-valley valence band of SnTe.

Table 1: Carrier concentration $\left(N_{p}\right)$ and effective mass $\left(\mathrm{m}^{*}\right.$, in term of the electron mass $\left.m_{e}\right)$ for $\mathrm{Sn}_{1.03-x} \mathrm{Ga}_{x} \mathrm{Te}(\mathrm{x}=0,0.02,0.03,0.05,0.07$ and 0.1$)$ samples at $300 \mathrm{~K}$.

\begin{tabular}{lll}
\hline Compositions & $N_{p}\left(10^{20} \mathrm{~cm}^{-3}\right)$ & $m^{*}\left(m_{e}\right)$ \\
\hline $\mathrm{Sn}_{1.03} \mathrm{Te}$ & 0.77 & 0.133 \\
$\mathrm{Sn}_{1.01} \mathrm{Ga}_{0.02} \mathrm{Te}$ & 1.35 & 0.273 \\
$\mathrm{SnGa}_{0.03} \mathrm{Te}$ & 2.1 & 0.44 \\
$\mathrm{Sn}_{0.98} \mathrm{Ga}_{0.05} \mathrm{Te}$ & 2.4 & 0.54 \\
$\mathrm{Sn}_{0.96} \mathrm{Ga}_{0.07} \mathrm{Te}$ & 3.3 & 0.8 \\
$\mathrm{Sn}_{0.93} \mathrm{Ga}_{0.1} \mathrm{Te}$ & 1.94 & 0.62 \\
\hline
\end{tabular}



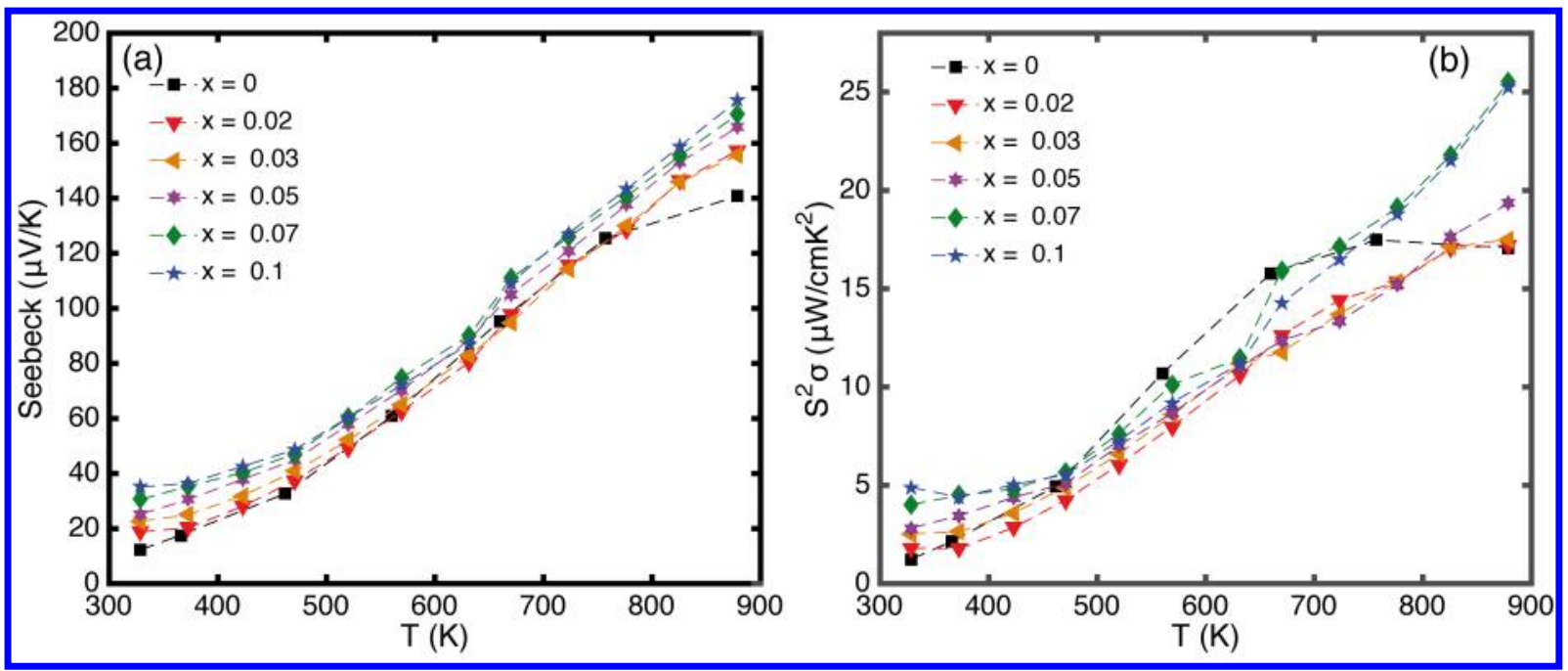

Figure 5: (a) Temperature dependence of Seebeck coefficient $(S)$ (b) and power factor $\left(S^{2} \sigma\right)$ of $\mathrm{Sn}_{1.03-x} \mathrm{Ga}_{x} \mathrm{Te}(\mathrm{x}=0,0.02,0.03,0.05,0.07$ and 0.1$)$ samples.

The temperature-dependent power factors of $\mathrm{Sn}_{1.03-x} \mathrm{Ga}_{x} \mathrm{~T}$ are plotted in (Figure $5 \mathrm{~b}$ ). Due to the enhancement in the Seebeck coefficient at both low and high temperatures, the Ga-doped samples have much higher values than the pure SnTe samples. For instance, the power factor increases from $2 \mu W \mathrm{~cm}^{-1} K^{-2}$ to $5 \mu W \mathrm{~cm}^{-1} K^{-2}$ at room temperature and from $16 \mathrm{Wcm}^{-1} \mathrm{~K}^{-2}$ to $26 \mathrm{Wcm}^{-1} \mathrm{~K}^{-2}$ at high temperature. The highest power factor obtained is $26 \mathrm{Wcm}^{-1} \mathrm{~K}^{-2}$ at $873 \mathrm{~K}$ for $\mathrm{Sn}_{0.96} \mathrm{Ga}_{0.07} \mathrm{Te}$. This power factor values achieved with Gadoped SnTe are comparable to those of PbTe. ${ }^{12,29,59}$ Although, the power factors saturate for $x \geq 0.07$ due to the presence of GaTe second phase (Figure 1a) which deteriorates the carrier mobility, the Seebeck coefficient (Figure 5a) is unaffected.

Aiming to clarify the improved electronic properties, we performed DFT calculations to determine the electronic structure of pristine SnTe and 6\% Ga-doped SnTe. It was proved that the band structure of pure SnTe does not favor large thermoelectric performances because of the value of band gap $\left(E_{g}=0.12 \mathrm{eV}\right)$ below the optimal one predicted by Goldsmid-Sharp formula, ${ }^{60}$ low effective masses associated with the dispersive character of valence bands active in transport, and the large offset between the light and heavy holes $(\Delta E \sim 0.35 \mathrm{eV})$ at $300 \mathrm{~K}$. However, upon proper alloying with $\mathrm{Ca} / \mathrm{Mg} / \mathrm{Cd} / \mathrm{Mn} / \mathrm{Hg} / \mathrm{Sb}$ in SnTe, the energy separation, $\Delta E$, significantly decreases opening the possibility to improve 
the thermoelectric properties adding carriers from multiple band extrema with different effective masses.

The projected density of states (PDOS) of $\mathrm{Sn}_{32} \mathrm{Te}_{32}$ and $\mathrm{Sn}_{30} \mathrm{Ga}_{2} \mathrm{Te}_{32}$ supercells are shown in Figure 6a and b, respectively. Contrary to Ca-, Mg-, Cd-, Mn-, and Hg-doping in SnTe, Ga-doping does not affect the energy separation between the electronic states at the top of the valence band (that are empty states after doping) and the electronic states at the bottom of the conduction band (we obtained $E_{g}=0.12 \mathrm{eV}$ for SnTe in agreement with recent experimental data). ${ }^{5}$ Ga alloying in $\mathrm{SnTe}$ does not seem to create resonant states, which are characterized by humps in proximity of the Fermi level. ${ }^{43}$

As shown in Figures 6c and $3(\mathrm{SI})$, the energy gap between valence and conduction manifolds is direct for all concentrations. Just below the top of the valence band, several other bands are present and may contribute to the transport properties with appropriate tuning of $\Delta E$ and the position of the Fermi level. Since the substitution of Sn by Ga decreases the number of electrons, the Fermi level moves downward as the amount of Ga doping increases. The maximum between $R$ and $X$ in the BZ (see Figure 6c) is quasidegenerate with the pockets in the $\Gamma-R$ and $\Gamma-X$ directions. Interestingly, we found that such a maximum occurs away from the symmetry line greatly increasing the number of degenerate valleys that contribute to the electronic transport.

In order to assess the performance with respect to other compositions, we compiled data available from the literature ${ }^{5,6,33,38,43,61,62}$ with our results using $S$ vs. $N_{p}$ plot for $\mathrm{Sn}_{1.03-x} \mathrm{Ga}_{x}$ Te samples (we used room temperature data) and compared with the theoretical curve (Pisarenko plot) obtained within a simple valence band model by Zhang et al. ${ }^{43}$ This model used a light-hole band effective mass of $0.168 m_{e}$, a heavy-hole band effective mass of $1.92 m_{e}$, and an energy gap between the two valence band maxima of $0.35 \mathrm{eV}$. The data for $\mathrm{Cu}, \mathrm{Sb}$ and Bi doped and un-doped SnTe samples fall exactly on the Pisarenko curve, while the In, $\mathrm{Ca} / \mathrm{Cd} / \mathrm{Hg} / \mathrm{Mg}$ alloyed SnTe samples show much higher Seebeck coefficient than the theoretical curve due to the formation of resonance levels, ${ }^{43}$ and/or an optimized multi- 
valley band structure near the Fermi level. ${ }^{5,6,38}$ Our Ga-doped SnTe samples also display larger Seebeck coefficients than the Pisarenko curve.
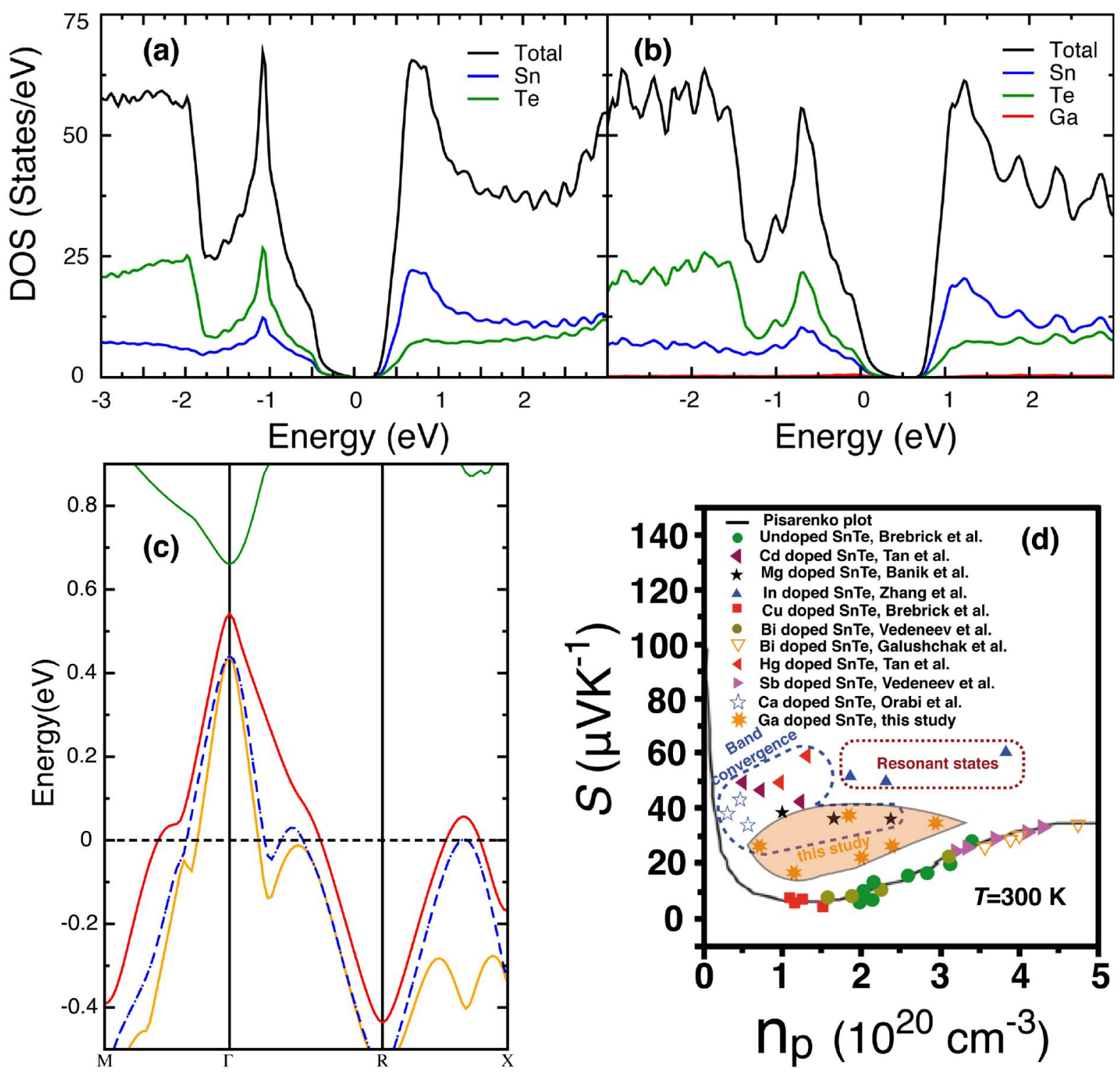

Figure 6: Density of states calculations of (a) undoped $\mathrm{SnTe}\left(\mathrm{Sn}_{32} \mathrm{Te}_{32}\right)$, (b) x $\sim 6 \%$ Ga-doped $\mathrm{SnTe}$ $\left(\mathrm{Sn}_{30} \mathrm{Ga}_{2} \mathrm{Te}_{32}\right)$. (c) Electronic band structure calculations of $\sim 6 \%$ Ga-doped $\mathrm{SnTe}\left(\mathrm{Sn}_{30} \mathrm{Ga}_{2} \mathrm{Te}_{32}\right)$ cubic supercell computed from DFT and (d) room temperature $S$ vs. $N_{p}$ plot. Data are from this work for $\mathrm{Sn}_{1.03-x} \mathrm{Ga}_{x} \mathrm{Te}$ and from previously reported experiments for pure $\mathrm{SnTe},{ }^{61}$ and $\mathrm{Cd}_{-},{ }^{38} \mathrm{Mg}_{-},{ }^{5} \mathrm{In}_{-},{ }^{43} \mathrm{Cu}_{-},{ }^{62}$ $\mathrm{Bi}-,{ }^{33} \mathrm{Hg}-,{ }^{6} \mathrm{Sb}-{ }^{33} \mathrm{Ca}$-doping. ${ }^{9}$ The theoretical Pisarenko curve is also plotted. ${ }^{43}$

The overall thermoelectric performances are shown in Figure 7a where we plot the temperature dependent figure of merit, $Z T$, for all our samples. Benefiting from the great reduction of lattice thermal conductivity and enhanced power factor, $Z T$ in $\mathrm{SnTe}$ is greatly 
enhanced by Ga doping, with the highest value reaching $\sim 1$ at $873 \mathrm{~K}$ in $\mathrm{Sn}_{0.96} \mathrm{Ga}_{0.07} \mathrm{Te}$. This value is $\sim 80 \%$ improved with respect to $\mathrm{Sn}_{1.03}$ Te and higher to previously reported maximum ZT with $\mathrm{Cd} / \mathrm{Bi} / \mathrm{Sb}$ and In singly doped $\mathrm{SnTe}$ (Figure 7b), and also outperforms other $p$-type lead-free thermoelectric materials (Figure 7c).

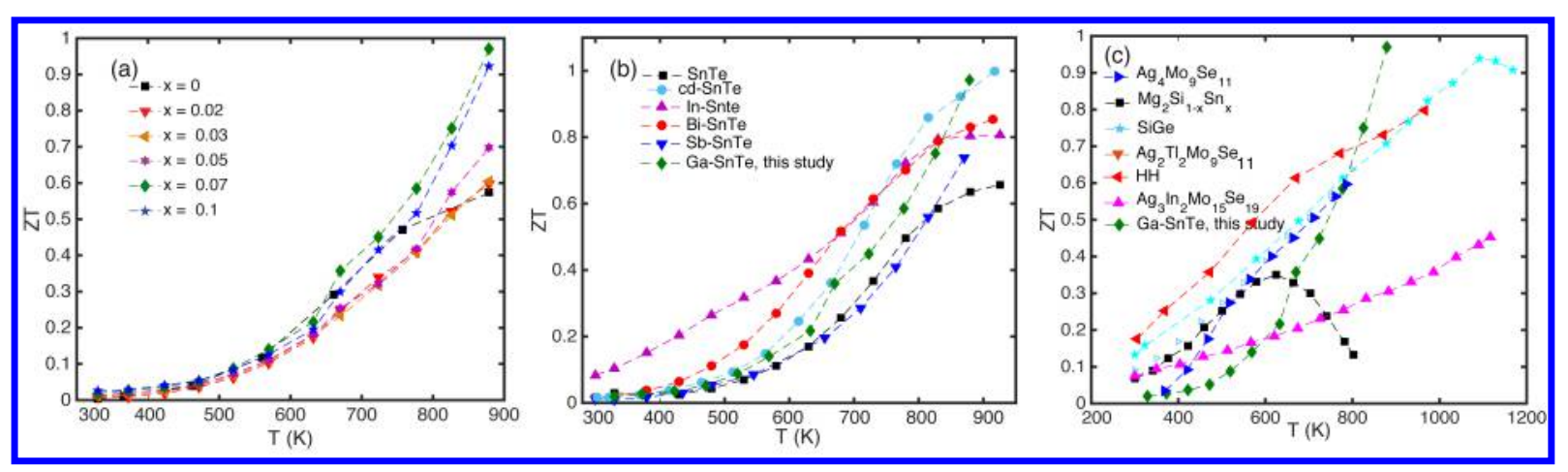

Figure 7: (a) The thermoelectric figure of merit $(Z T)$ as a function of temperature for $\mathrm{Sn}_{1.03-x} \mathrm{Ga}_{x} \mathrm{Te}$ $\left(\mathrm{x}=0,0.02,0.03,0.05,0.07\right.$ and 0.1) samples.(b) Comparison of $Z T$ values for pure SnTe, $\mathrm{In}-{ }^{43} \mathrm{Cd}-{ }^{38}$, Bi-doped ${ }^{44}$, Sb-doped ${ }^{54}$ systems, and our results for Ga-doping SnTe, (c) Comparison of $Z T$ of Ga-doped SnTe (this study) with some the best $p$-type lead-free thermoelectric materials including skutterudites, ${ }^{63}$ $\mathrm{AgSn}_{x} \mathrm{SbTe}_{2+x},{ }^{64} \mathrm{Mg}_{2} \mathrm{Si}_{1+x} \mathrm{Sn}_{x},{ }^{65} \mathrm{Si}-\mathrm{Ge}$ alloy, ${ }^{66}$ complex molybdenum chalcogenide ${ }^{15-17}$ and half-Heusler ${ }^{67}$ materials.

\section{Conclusions}

We have synthesized high quality samples of Ga-doped SnTe spanning Ga concentration from $2 \%$ to $10 \%$. The substitution of Sn with Ga lower substantially the lattice thermal conductivity to the point of reaching the amorphous limit at high temperature with $7-10 \%$ Ga-doping. The phenomenon is understood by XRD and SEM/EDS analysis that indicate the formation of GaTe nano-precipitates. Remarkably, the electronic transport properties are also improved by Ga-doping due to the activation of several hole pockets in the valence band as indicated by first principles calculations. The combination of ultra-low lattice thermal conductivity with power factors in excess of $25 \mathrm{Wcm}^{-1} \mathrm{~K}^{-2}$ at high temperature increased the figure of merit, $Z T$, from 0.40 in pristine SnTe to $\sim 1$ in 7\% Ga-doped SnTe samples. The improved performances make Ga-doped SnTe a serious candidate for medium temperature thermoelectric power generation when toxic-free materials are desired. 


\section{Acknowledgement}

R. A. R. A. O. and D. W. thank Solvay Special Chemicals for financial support. This work was partially supported by Mid-career Researcher Program (No. 2011-0028729) and Nano.Material Technology Development Program (No. 2011-0030147) through the National Research Foundation of Korea (NRF) grant funded by the Ministry of Education, Science and Technology (MEST). Computations were performed at the Institut des Sciences Chimiques de Rennes and at the High Performance Computing Center, Michigan State University. M. F. acknowledges collaboration with the AFLOW Consortium (http://www.aflow.org) under the sponsorship of DOD-ONR (N000141310635 and N000141512266).

\section{Supporting Information Available}

Input parameters for the calculation based on the Klemens; model at $300 \mathrm{~K}$,thermal diffusivity, calculated Lorenz number as a function of $\mathrm{x}$ for $\mathrm{Sn}_{1.03-x} \mathrm{Ga}_{x} \mathrm{Te}(\mathrm{x}=0,0.02,0.03$, 0.05, 0.07 and 0.09 ); thermoelectric properties of $\mathrm{Sn}_{0.96} \mathrm{Ga}_{0.07} \mathrm{Te}$ sample of initial and reproduced measurment; total electronic band structure on function of $\mathrm{BZ}$ of $\mathrm{Sn}_{32} \mathrm{Te}_{32}$, and $\mathrm{Sn}_{30} \mathrm{Ga}_{2} \mathrm{Te}_{32}$ cubic supercells; Powder XRD patterns for $\mathrm{Sn}_{1.03-x} \mathrm{Ga}_{x} \mathrm{Te}(\mathrm{x}=$ 0, 0.02, 0.03, 0.05, 0.07 and 0.09$)$ samples. This material is available free of charge via the Internet at http://pubs.acs.org/.

\section{References}

(1) Snyder, G. J.; Toberer, E. S. Complex Thermoelectric Materials. Nat. Mater 2008, 7, 105-114.

(2) Slack, G. A., Ed. in Thermoelectrics Handbook: Macro to Nano, Eds., D. M. Rowe, CRC Press; 1995.

(3) Koumoto, T., K.and Mori, Ed. In Thermoelectric Nanomaterials; 2013. 
(4) Nolas, G. S.; Sharp, J.; Goldsmid, J. Thermoelectrics: Basic Principles and New Materials Developments; Springer Series in Materials Science: Berlin, 2001; Vol. 45.

(5) Banik, A.; Shenoy, U. S.; Anand, S.; Waghmare, U. V.; Biswas, K. Mg Alloying in SnTe Facilitates Valence Band Convergence and Optimizes Thermoelectric Properties. Chem. Mater. 2015, 27, 581-587.

(6) Tan, G.; Shi, F.; Doak, J. W.; Sun, H.; Zhao, L.-D.; Wang, P.; Uher, C.; Wolverton, C.; Dravid, V. P.; Kanatzidis, M. G. Extraordinary role of Hg in enhancing the thermoelectric performance of p-type SnTe. Enerau Environ.Sci. 2015, 8, 267-277.

(7) Tan, G.; Shi, F.; Hao, S.; Chi, H.; Bailey, T. P.; Zhao, L.-D.; Uher, C.; Wolverton, C.; Dravid, V. P.; Kanatzidis, M. G. Valence Band Modification and High Thermoelectric Performance in SnTe Heavily Alloyed with MnTe. J.Am.Chem.Soc. 2015, 137, 1150711516.

(8) Wu, H.; Chang, C.; Feng, D.; Xiao, Y.; Zhang, X.; Pei, Y.; Zheng, L.; Wu, D.; Gong, S.; Chen, Y.; He, J.; Kanatzidis, M. G.; Zhao, L.-D. Synergistically optimized electrical and thermal transport properties of SnTe via alloying high-solubility MnTe. Energy Environ. Sci. 2015, 8, 3298-3312.

(9) Al Rahal Al Orabi, R.; Mecholsky, N. A.; Hwang, J.; Kim, W.; Rhyee, J.-S.; Wee, D.; Fornari, M. Band Degeneracy, Low Thermal Conductivity, and High Thermoelectric Figure of Merit in SnTe-CaTe Alloys. Chem. Mater. 2016, 28, 376-384.

(10) Tanryverdiev, V. S.; Aliev, O. M. Restoring the Density-Gradient Expansion for Exchange in Solids and Surfaces. Inorg. Mater. 1995, 31, 1362.

(11) Carrete, J.; Li, W.; Mingo, N.; Wang, S.; Curtarolo, S. Finding Unprecedentedly LowThermal-Conductivity Half-Heusler Semiconductors via High-Throughput Materials Modeling. Phus. Rev. X 2014, 4, 011019. 
(12) Biswas, K.; He, J.; Wang, G.; Lo, S.-H.; Uher, C.; Dravid, V. P.; Kanatzidis, M. G. High Thermoelectric Figure of Merit in Nanostructured p-Type PbTe-MTe (M = Ca, Ba). Enerau Environ. Sci. 2011, 4, 4675-4684.

(13) Wang, H.; Bahk, J.-H.; Kang, C.; Hwang, J.; Kim, K.; Shakouri, A.; Kim, W. Large Enhancement in the Thermoelectric Properties of $\mathrm{Pb}_{0.98} \mathrm{Na}_{0.02}$ Te by Optimizing the Synthesis Conditions. J. Mater. Chem.A 2013, 1, 11269-11278.

(14) Wang, H.; Bahk, J.-H.; Kang, C.; Hwang, J.; Kim, K.; Kim, J.; Burke, P.; Bowers, J. E.; Gossard, A. C.; Shakouri, A.; Kim, W. Right Sizes of Nano- and Microstructures for High-Performance and Rigid Bulk Thermoelectrics. Proc. Natl. Acad. Sci. 2014, 111, 10949-10954.

(15) Al Rahal Al Orabi, R.; Gougeon, P.; Gall, P.; Fontaine, B.; Gautier, R.; Colin, M.; Candolfi, C.; Dauscher, A.; Hejtmanek, J.; Malaman, B.; Lenoir, B. X-ray Characterization, Electronic Band Structure, and Thermoelectric Properties of the Cluster Compound $\mathrm{Ag}_{2} \mathrm{Tl}_{2} \mathrm{Mog}_{9} \mathrm{Se}_{11}$. Inora. Chem. 2014, 53, 11699-11709.

(16) Zhou, T.; Lenoir, B.; Colin, M.; Dauscher, A.; Al Rahal Al Orabi, R.; Gougeon, P.; Potel, M.; Guilmeau, E. Promising thermoelectric properties in $\mathrm{Ag}_{x} \mathrm{Mog}_{9} \mathrm{Se}_{11}$ compounds $(3.4 \leq \mathrm{x} \leq 3.9)$. App.Phys. Lett. 2011, 98 .

(17) Gougeon, P.; Gall, P.; Al Rahal Al Orabi, R.; Fontaine, B.; Gautier, R.; Potel, M.; Zhou, T.; Lenoir, B.; Colin, M.; Candolfi, C.; Dauscher, A. Synthesis, Crystal and Electronic Structures, and Thermoelectric Properties of the Novel Cluster Compound $\mathrm{Ag}_{3} \mathrm{In}_{2} \mathrm{Mo}_{15} \mathrm{Se}_{19}$. Chem. Mater. 2012, 24, 2899-2908.

(18) Al Rahal Al Orabi, R.; Fontaine, B.; Gautier, R.; Gougeon, P.; Gall, P.; Bouyrie, Y.; Dauscher, A.; Candolfi, C.; Lenoir, B. Cu Insertion Into the Mo12 Cluster Compound Cs2Mo12Se14: Synthesis, Crystal and Electronic Structures, and Physical Properties. Inora Chem. 2016, 55, 6616-6624. 
(19) Vaqueiro, P.; Al Rahal Al Orabi, R.; Luu, S. D. N.; Guelou, G.; Powell, A. V.; Smith, R. I.; Song, J.-P.; Wee, D.; Fornari, M. The role of copper in the thermal conductivity of thermoelectric oxychalcogenides: do lone pairs matter? Phys. Chem. Chem. Phys. 2015, 17, 31735-31740.

(20) Wee, D.; Kozinsky, B.; Marzari, N.; Fornari, M. Effects of filling in CoSb $_{3}$ : Local structure, band gap, and phonons from first principles. Phys. Rev. B 2010, 81, 045204.

(21) Bang, S.; Wee, D.; Li, A.; Fornari, M.; Kozinsky, B. Thermoelectric properties of pnictogen-substituted skutterudites with alkaline-earth fillers using first-principles calculations. J. Appl. Phys. 2016, 119.

(22) Al Rahal Al Orabi, R.; Orisakwe, E.; Wee, D.; Fontaine, B.; Gautier, R.; Halet, J.F.; Fornari, M. Prediction of high thermoelectric potential in $\mathrm{AMN}_{2}$ layered nitrides: electronic structure, phonons, and anharmonic effects. J. Mater. Chem. A 2015, 3, 9945-9954.

(23) Biswas, K.; He, J.; Blum, I. D.; Wu, C.-I.; Hogan, T. P.; Seidman, D. N.; Dravid, V. P.; Kanatzidis, M. G. High-Performance Bulk Thermoelectrics With All-Scale Hierarchical Architectures. Nature 2012, 489, 414-418.

(24) Biswas, K.; He, J.; Zhang, Q.; Wang, G.; Uher, C.; Dravid, V. P.; Kanatzidis, M. G. Strained Endotaxial Nanostructures With High Thermoelectric Figure of Merit. Nat. Chem. 2012, 3, 160-166.

(25) Wang, H.; Hwang, J.; Snedaker, M. L.; Kim, I.-h.; Kang, C.; Kim, J.; Stucky, G. D.; Bowers, J.; Kim, W. High Thermoelectric Performance of a Heterogeneous PbTe Nanocomposite. Chem. Mater. 2015, 27, 944-949.

(26) Gelbstein, Y.; Rosenberg, Y.; Sadia, Y.; Dariel, M. P. Thermoelectric Properties Evolution of Spark Plasma Sintered $\left(\mathrm{Ge}_{0.6} \mathrm{~Pb}_{0.3} \mathrm{Sn}_{0.1}\right)$ Te Following a Spinodal Decomposition. J. Phus. Chem. C 2010, 114, 13126-13131. 
(27) Gelbstein, Y.; Dashevsky, Z.; Dariel, M. P. Highly efficient bismuth telluride doped p-type $\mathrm{Pb}_{0.13} \mathrm{Ge}_{0.87} \mathrm{Te}$ for thermoelectric applications. Phys. Stat. Sol. RRL 2007, 1, $232-234$.

(28) Gelbstein, Y.; Davidow, J.; Girard, S. N.; Chung, D. Y.; Kanatzidis, M. Controlling Metallurgical Phase Separation Reactions of the $\mathrm{Ge}_{0.87} \mathrm{~Pb}_{0.13}$ Te Alloy for High Thermoelectric Performance. Adv. Enerau Mater. 2013, 3, 815-820.

(29) Zhao, L. D.; Wu, H. J.; Hao, S. Q.; Wu, C. I.; Zhou, X. Y.; Biswas, K.; He, J. Q.; Hogan, T. P.; Uher, C.; Wolverton, C.; Dravid, V. P.; Kanatzidis, M. G. All-Scale Hierarchical Thermoelectrics: MgTe in PbTe Facilitates Valence Band Convergence and Suppresses Bipolar Thermal Transport for High Performance. Energy Environ. Sci. 2013, 6, 3346-3355.

(30) Ginting, D.; Lin, C.-C.; Rathnam, L.; Yu, B.-K.; Kim, S.-J.; Al Rahal Al Orabi, R.; Rhyee, J.-S. Enhancement of thermoelectric properties by effective K-doping and nano precipitation in quaternary compounds of $\left(\mathrm{Pb}_{1-x} \mathrm{~K}_{x} \mathrm{Te}\right)_{0.70}(\mathrm{PbSe})_{0.25}(\mathrm{PbS})_{0.05}$. RSC Adv. 2016, 6, 62958-62967.

(31) Zhao, L.-D.; Lo, S.-H.; Zhang, Y.; Sun, H.; Tan, G.; Uher, C.; Wolverton, C.; Dravid, V. P.; Kanatzidis, M. G. Ultralow thermal conductivity and high thermoelectric figure of merit in SnSe crystals. Nature 2015, 508, 373-377.

(32) Zhao, L.-D.; Tan, G.; Hao, S.; He, J.; Pei, Y.; Chi, H.; Wang, H.; Gong, S.; Xu, H.; Dravid, V. P.; Uher, C.; Snyder, G. J.; Wolverton, C.; Kanatzidis, M. G. Ultrahigh power factor and thermoelectric performance in hole-doped single-crystal SnSe. Science 2016, 351, 141-144.

(33) Vedeneev, V.; Krivoruchko, S.; Sabo, E. Tin Telluride Based Thermoelectrical Alloys. Semiconductors 1998, 32, 241-244. 
(34) Rogers, L. M. High Thermoelectric Performance of a Heterogeneous PbTe Nanocomposite. J.Phus. D: Appl. Phus. 1968, 1, 845.

(35) He, J.; Xu, J.; Liu, G.-Q.; Shao, H.; Tan, X.; Liu, Z.; Xu, J.; Jiang, H.; Jiang, J. Enhanced thermopower in rock-salt SnTe-CdTe from band convergence. $R S C A d v \mathbf{2 0 1 6}$, $6,32189-32192$.

(36) Esaki, L.; Stiles, P. J. New Type of Negative Resistance in Barrier Tunneling. Phys. Rev.Lett. 1966, 16, 1108-1111.

(37) Dimmock, J. O.; Melngailis, I.; Strauss, A. J. Band Structure and Laser Action in $\mathrm{Pb}_{x} \mathrm{Sn}_{1-x}$ Te. Phus. Rev. Lett. 1966, 16, 1193-1196.

(38) Tan, G.; Zhao, L.-D.; Shi, F.; Doak, J. W.; Lo, S.-H.; Sun, H.; Wolverton, C.; Dravid, V. P.; Uher, C.; Kanatzidis, M. G. High Thermoelectric Performance of pType SnTe via a Synergistic Band Engineering and Nanostructuring Approach. J. Am. Chem.Soc. 2014, 136, 7006-7017.

(39) He, J.; Tan, X.; Xu, J.; Liu, G.-Q.; Shao, H.; Fu, Y.; Wang, X.; Liu, Z.; Xu, J.; Jiang, H.; Jiang, J. Valence band engineering and thermoelectric performance optimization in SnTe by Mn-alloying via a zone-melting method. J.Mater. Chem.A 2015, 3, 1997419979.

(40) Tan, X. J.; Liu, G. Q.; Xu, J. T.; Shao, H. Z.; Jiang, J.; Jiang, H. C. Element-selective resonant state in M-doped $\operatorname{SnTe}(\mathrm{M}=\mathrm{Ga}$, In, and $\mathrm{Tl})$. Phys. Chem. Chem. Phys. 2016, 18, 20635-20639.

(41) Tan, X. J.; Shao, H. Z.; He, J.; Liu, G. Q.; Xu, J. T.; Jiang, J.; Jiang, H. C. Band engineering and improved thermoelectric performance in M-doped $\operatorname{SnTe}(\mathrm{M}=\mathrm{Mg}, \mathrm{Mn}$, Cd, and Hg). Phus. Chem. Chem. Phus. 2016, 18, 7141-7147. 
(42) Tan, G.; Zeier, W. G.; Shi, F.; Wang, P.; Snyder, G. J.; Dravid, V. P.; Kanatzidis, M. G. High Thermoelectric Performance $\mathrm{SnTe}-\mathrm{In}_{2} \mathrm{Te}_{3}$ Solid Solutions Enabled by Resonant Levels and Strong Vacancy Phonon Scattering. Chem. Mater. 2015, 27, 7801-7811.

(43) Zhang, Q.; Liao, B.; Lan, Y.; Lukas, K.; Liu, W.; Esfarjani, K.; Opeil, C.; Broido, D.; Chen, G.; Ren, Z. High Thermoelectric Performance by Resonant Dopant Indium in Nanostructured SnTe. Proc. Natl. Acad.Sci. U.S.A. 2013, 110, 13261-13266.

(44) Zhao, L.-D.; Zhang, X.; Wu, H.; Tan, G.; Pei, Y.; Xiao, Y.; Chang, C.; Wu, D.; Chi, H.; Zheng, L.; Gong, S.; Uher, C.; He, J.; Kanatzidis, M. G. Enhanced Thermoelectric Properties in the Counter-Doped SnTe System with Strained Endotaxial SrTe. J. Am. Chem.Soc. 2016, 138, 2366-2373.

(45) Tan, G.; Shi, F.; Hao, S.; Chi, H.; Zhao, L.-D.; Uher, C.; Wolverton, C.; Dravid, V. P.; Kanatzidis, M. G. Codoping in SnTe: Enhancement of Thermoelectric Performance through Synergy of Resonance Levels and Band Convergence. J. Am. Chem. Soc. 2015, $137,5100-5112$.

(46) Tan, G.; Shi, F.; Sun, H.; Zhao, L.-D.; Uher, C.; Dravid, V. P.; Kanatzidis, M. G. $\mathrm{SnTe}-\mathrm{AgBiTe}_{2}$ as an efficient thermoelectric material with low thermal conductivity. $J$. Mater. Chem.A 2014, 2, 20849-20854.

(47) Zhang, Q.; Cao, F.; Lukas, K.; Liu, W.; Esfarjani, K.; Opeil, C.; Broido, D.; Parker, D.; Singh, D. J.; Chen, G.; Ren, Z. Study of the Thermoelectric Properties of Lead Selenide Doped with Boron, Gallium, Indium, or Thallium. J. Am. Chem. Soc. 2012, 134, $17731-17738$.

(48) Wagner, M. heat-cpecific. These de Doctorat, Universitat Wien 2007,

(49) Blaha, P.; Schwarz, K.; Madsen, G. K. H.; Kvasnicka, D.; Luitz, J. WIEN2K, An Augmented Plane Wave + Local Orbitals Program for Calculating Crystal Properties; Karlheinz Schwarz, Techn. Universität Wien, Austria, 2001. 
(50) Tran, F.; Blaha, P. Accurate Band Gaps of Semiconductors and Insulators with a Semilocal Exchange-Correlation Potential. Phus.Rev._Lett. 2009, 102, 226401.

(51) May, A. F.; Toberer, E. S.; Saramat, A.; Snyder, G. J. Characterization and analysis of thermoelectric transport in $n$-type $\mathrm{Ba}_{8} \mathrm{Ga}_{16-x} \mathrm{Ge}_{30+x}$. Phus. Rev. B 2009, 80, 125205.

(52) Cahill, D. G.; Watson, S. K.; Pohl, R. O. Lower Limit to the Thermal Conductivity of Disordered Crystals. Phus. Rev. B: Condens. Matter Mater Phus. 1992, 46, 6131-6140.

(53) Tan, G.; Shi, F.; Hao, S.; Zhao, L.-D.; Chi, H.; Zhang, X.; Uher, C.; Wolverton, C.; Dravid, V. P.; Kanatzidis, M. G. Non-equilibrium processing leads to record high thermoelectric figure of merit in PbTe-SrTe. Nat. Commun. 2016, 7, 12167.

(54) Banik, A.; Vishal, B.; Perumal, S.; Datta, R.; Biswas, K. The origin of low thermal conductivity in $\mathrm{Sn}_{1-x} \mathrm{Sb}_{x}$ Te: phonon scattering via layered intergrowth nanostructures. Enerau Environ.Sci. 2016, 9, 2011-2019.

(55) Abeles, B. Lattice Thermal Conductivity of Disordered Semiconductor Alloys at High Temperatures. Phus. Rev. 1963, 131, 1906-1911.

(56) Eshelby, J. D. Lattice Thermal Conductivity of Disordered Semiconductor Alloys at High Temperatures. Acta Metall. 1955, 3, 487.

(57) Klemens, P. G. Thermal Resistance due to Point Defects at High Temperatures. Phys. Rev. 1960, 119, 507-509.

(58) Toberer, E. S.; Zevalkink, A.; Crisosto, N.; , G. J. The Zintl Compound $\mathrm{Ca}_{5} \mathrm{Al}_{2} \mathrm{Sb}_{6}$ for Low-Cost Thermoelectric Power Generation. Adv.Funct. Mater. 2010, 20, 4375-4380.

(59) Pei, Y.; LaLonde, A.; Iwanaga, S.; Snyder, G. J. High thermoelectric figure of merit in heavy hole dominated PbTe. EnerauEnviron.SSi. 2011, 4, 2085-2089.

(60) Goldsmid, H.; Sharp, J. Estimation of the Thermal Band Gap of a Semiconductor From Seebeck Measurements. J. Electron. Mater. 1999, 28, 869-872. 
(61) Brebrick, R. F.; Strauss, A. J. Anomalous Thermoelectric Power as Evidence for TwoValence Bands in SnTe. Phus. Rev. 1963, 131, 104-110.

(62) Brebrick, R. Deviations From Stoichiometry and Electrical Properties in SnTe. J. Phys. Chem. Solids 1963, 24, $27-36$.

(63) Tan, G.; Zheng, Y.; Tang, X. Semiconducting Ge Clathrates: Promising Candidates for Thermoelectric Applications. Appl. Phus._Lett. 2013, 103, 183904.

(64) Han, M.-K.; Androulakis, J.; Kim, S.-J.; Kanatzidis, M. G. Lead-Free Thermoelectrics: High Figure of Merit in p-type $\mathrm{AgSn}_{m} \mathrm{SbTe}_{m+2}$. Adv. Enerau Mater. 2012, 2, 157-161.

(65) Liu, W.; Yin, K.; Su, X.; Li, H.; Yan, Y.; Tang, X.; Uher, C. Enhanced Hole Concentration Through Ga Doping and Excess of Mg and Thermoelectric Properties of p-Type $\mathrm{Mg}_{2(1+z)}\left(\mathrm{Si}_{0.3} \mathrm{Sn}_{0.7}\right)_{y} \mathrm{Ga}_{y}$. Intermetallics 2013, 32, 352 - 361 .

(66) Joshi, G.; Lee, H.; Lan, Y.; Wang, X.; Zhu, G.; Wang, D.; Gould, R. W.; Cuff, D. C.; Tang, M. Y.; Dresselhaus, M. S.; Chen, G.; Ren, Z. Enhanced Thermoelectric Figureof-Merit in Nanostructured p-type Silicon Germanium Bulk Alloys. Nano Letters 2008, 8, 4670-4674.

(67) Yan, X.; Joshi, G.; Liu, W.; Lan, Y.; Wang, H.; Lee, S.; Simonson, J. W.; Poon, S. J.; Tritt, T. M.; Chen, G.; Ren, Z. F. Enhanced Thermoelectric Figure of Merit of p-Type Half-Heuslers. Nano Letters 2011, 11, 556-560. 


\section{Graphical TOC Entry}

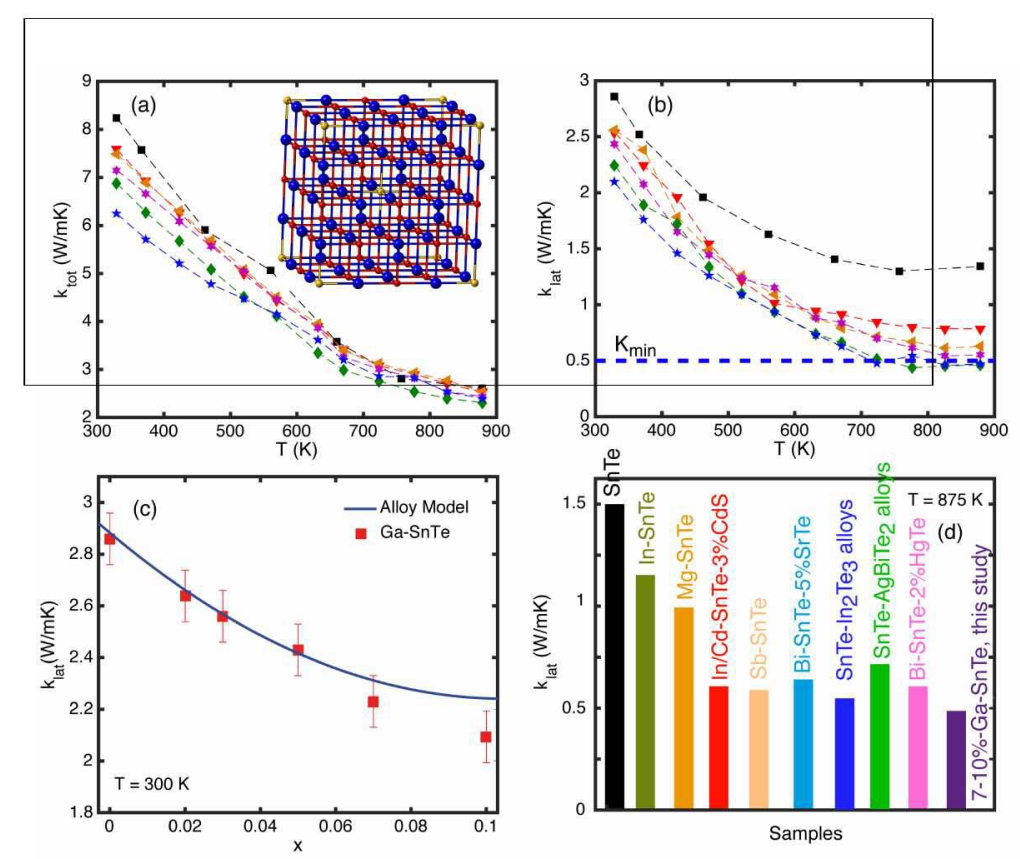

